\title{
Glucose Production in the Newborn Dog. II. Evaluation of Autonomic and Enzymatic Control in the Isolated Perfused Canine Liver
}

\author{
ROWAN T. CHLEBOWSKI AND PETER A. J. 'ADAM ${ }^{(48)}$ \\ Department of Pediatrics, Case Western Reserve University School of Medicine at Cleveland Metropolitan General \\ Hospital, Cleveland, Ohio, USA
}

\section{Extract}

The effects of birth and norepinephrine on hepatic glucose production, glycogenolysis, and gluconeogenesis were examined in livers isolated from fetal dogs at term, littermates $3 \mathrm{hr}$ after delivery, and newborn dogs 1-5 days old. Livers were perfused in pairs with medium containing $\left[6-{ }^{3} \mathrm{H}\right]$ glucose $(6 \mathrm{mM})$ and $\left[3-{ }^{14} \mathrm{C}\right] \mathrm{lac}-$ tate $(10 \mathrm{mM}) \pm$ a pharmacologic amount of norepinephrine $\left(10^{-6}\right.$ $M)$. Changes in glucose production rates were correlated with changes in the enzymatic activities controling gluconeogenesis.

Net glucose production was $<0.48 \mu \mathrm{mol} / \mathrm{min}$. $\mathrm{g}$ liver in both fetal and $3 \mathrm{hr}$ liver but stabilized above $1 \mu \mathrm{mol} / \mathrm{min} \cdot \mathrm{g}$ later during the first day. Initially, mobilization of the fetal hepatic glycogen accounted for glucose output. Subsequently, incorporation of lactate into glucose rose from negligible fetal rates to $0.19 \mu \mathrm{mol} / \mathrm{min} \cdot \mathrm{g}$ and accounted for $21 \%$ of net glucose production on day 3 . Maximal pyruvate carboxylase activity and mitochondrial $\mathrm{CO}_{2}$ fixation increased postnatally and correlated directly with net glucose production, glucose production from glycogen, and glucose production from lactate.

Fetal liver did not respond to norepinephrine. Therafter, norepinephrine increased hepatic glucose production by stimulating glycogen breakdown. Postnatal acceleration of glucose production and the response to norepinephrine occurred only after induction of mitochondrial $\mathrm{CO}_{2}$ fixation. During day $l$ the decline of hepatic glycogen in response to norepinephrine correlated with both $\mathrm{CO}_{2}$ fixation and lactate incorporation into glucose. Thus, initiation of gluconeogenesis after birth may have been required for the postnatal acceration of hepatic glucose production and for the regulation of glycogenolysis by norepinephrine.

\section{Speculation}

A multiple system for hormonal plus neural initiation of hepatic glucose production after birth may protect the newborn mammal from cessation of the maternal supply of glucose and other substrates. Events such as relative hypoglycemia postnatally or intermittent hypoxia prenatally initiate pancreatic glucagon or sympathetic neural norepinephrine release, both of which stimulate hepatic glucose release. Shortly after birth, the target organ, liver, responds appropriately to both the pancreatic and neural hormones.

At birth, when the maternofetal transport of glucose ceases abruptly, the newborn infant or animal must establish hepatic glucose production at a physiologic rate in order to maintain the blood glucose concentration. This glucose may be derived from hepatic glycogenolysis or gluconeogenesis (1). The large hepatic glycogen stores present in the mammalian fetus at term decline postnatally in all species examined $(7,24)$. Gluconeogenesis by fetal liver slices is negligible in many species but increases during the first week of life $(6,30,34)$. The relative contributions of glycogenolysis and gluconeogenesis to total glucose production have not been determined during late fetal and early neonatal life.

In adult animals, hepatic glucose output is controlled partially by the sympathetic innervation of the liver via the splanchnic nerve. Splanchnic nerve stimulation increases hepatic phosphorylase activity in rabbits (26) and produces a hyperglycemic, glycogenolytic response in adrenalectomized animals of many species (8). The role of catecholamines in initiating hepatic glucose production at birth has not been determined; however, hyperglycemic responses to splanchnic nerve stimulation have been demonstrated in newborn calves in vivo (11), and surgical section of the splanchnic nerve during this period prevents the normal hyperglycemic response to hypoxia (10). Furthermore, intraperitoneal injection of norepinephrine in fetal rats induces prematurely hepatic enzymatic activities essential for gluconeogenesis (36).

In the present study, isolated livers were perfused to examine the ability of fetal and neonatal liver to produce glucose. Changes in glucose production rates were quantified during development and correlated with the activities of enzymes required for gluconeogenesis. In addition, the potential responses of hepatic glucose production to the sympathetic neural catecholamine in the newborn period was evaluated by perfusing fetal and neonatal canine liver with pharmacologic quantities of norepinephrine.

\section{EXPERIMENTAL PROCEDURE}

\section{MATERIALS}

Isotopic tracers were purchased from New England Nuclear (37) enzymes and chemicals from Sigma Chemical Corporation (38).

\section{ANIMALS}

Pedigree beagle bitches of known breeding dates were delivered surgically on the 60th day of gestation (term gestation $=60 \pm 2$ days) after anesthesia with intravenous diazepam and infiltration of the incision site with lidocaine.

Livers from surgically delivered dogs, perfused immediately after birth, were designated "fetal." Livers from resuscitated littermates, perfused $3 \mathrm{hr}$ after birth, were designated "3-hr premature." "Newborn" livers were studied on the 1st day between 6 and $24 \mathrm{hr}$, and on the 3rd and 5th day after either surgical or spontaneous delivery. After removal from the mother, body temperatures of the newborn dogs were maintained at $37^{\circ}$ with an incandescent lamp at an appropriate distance, while core temperatures were monitored with a rectal probe. Puppies delivered by cesarian section were fasted for $6 \mathrm{hr}$, and were fed a milk formula (Enfamil) every $3 \mathrm{hr}$ as tolerated. Naturally born pups were left to suckle ad libitum until $0.5 \mathrm{hr}$ before study. After day l, dogs delivered surgically and vaginally produced indistinguishable 
results during perfusion and were not separated for statistical evaluation. A total of 38 livers from 8 litters of newborn dogs were perfused. Six of the newborn dogs were perfused at a time when littermates were no longer available. Thus, data from 32 livers are reported in paired comparisons.

\section{TECHNIQUE OF PERFUSION}

The newborn dogs were restrained and a catheter inserted in the umbilical vein proximal to the liver. Then the liver was cooled by rapid infusion of Krebs-Ringer bicarbonate solution at $0^{\circ}$ containing glucose $6 \mathrm{mM}$ and the animal was decapitated simultaneously. During isolation the liver was continually perfused with the oxygenated KRB medium at $0^{\circ}$. The liver was excised and the accessory quadrate lobe isolated and removed. This liver sample was divided, a portion was placed in a solution of $0.3 \mathrm{M}$ sucrose at $0^{\circ}$ (to begin isolation of mitochondria for $\mathrm{CO}_{2}$ fixation and pyruvate carboxylase assays), and the rest was frozen immediately in isopentane at $-25^{\circ}$ for glycogen determination and the remaining enzyme assays. The isolated liver was connected to an extracorporeal perfusion unit (39) and perfused with recirculating medium via the umbilical venous catheter, with return collected in a warmed funnel from the hepatic vein.

The time of connection of the liver to the perfusion system was designated zero time $(0 \mathrm{~min})$. Perfusions were terminated after 60 min and the livers rapidly cleared of blood with cold KRB. The livers were biopsied again and the divided samples treated as

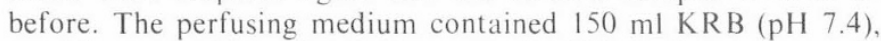
aged human red blood cells (hematocrit $10 \%$ ); hydrocortisone, 50 $\mathrm{mg}$; bovine albumin (fraction v (38)), $5 \mathrm{~g}$; penicillin, $5 \mathrm{mg}$; heparin, $25 \mathrm{mg}$; glucose $6 \mathrm{mM}$; lactate, $10 \mathrm{mM} ;\left[6-{ }^{3} \mathrm{H}\right]$ glucose, $25 \mu \mathrm{Ci}$; and either 3 -lactate or $\left[U-{ }^{14} \mathrm{C}\right]$ lactate $25 \mu \mathrm{Ci}$. The flow rate was 30 $\mathrm{ml} / \mathrm{min}$ at a temperature of $37^{\circ}$. The medium was aerated continuously with $95 \% \mathrm{O}_{2}-5 \% \mathrm{CO}_{2}$.

Glucose utilization by the aged red blood cells had been determined by recirculating medium containing 6,12 , or $24 \mathrm{mM}$ glucose through the perfusion apparatus at $37^{\circ}$ for $1 \mathrm{hr}$. The disappearance of glucose in all cases was negligible compared with liver perfusion results and never exceeded $0.08 \mu \mathrm{mol} / \mathrm{ml} / \mathrm{hr}$. Pilot studies in both adult rats and newborn dogs demonstrated that addition of hydrocortisone tended to stabilize mitochondrial $\mathrm{CO}_{2}$ fixation during perfusion of isolated livers without raising hepatic glucose production rates or altering the enzymatic activities.

Each study was performed with a pair of isolated livers obtained from littermates and perfused simultaneously on separate perfusion units. The control liver was perfused with the standard medium. The second liver was perfused with the standard medium containing norepinephrine bitartrate (40) at an initial concentration of $10^{-6} \mathrm{M}$. Medium norepinephrine concentration was maintained during perfusion by adding equal amounts of norepinephrine at 10 -min intervals. Two additional livers were similarly perfused with glucagon on the first day at an initial concentration of $10^{-6} \mathrm{M}$.

\section{MODEL}

The model used for the quantification of hepatic glucose production by perfused canine liver is illustrated using data from a representative pair of 5-day pups (Fig. 1). Both livers were perfused with substrate $\mathrm{L}-\left[3-{ }^{14} \mathrm{C}\right]$ lactate at an initial concentration of $10 \mathrm{mM}$. In addition, one liver of the pair was perfused with norepinephrine $\left(10^{-6} \mathrm{M}\right)$. Glucose was added at an initial concentration of $6 \mathrm{mM}$ and rose continuously during the perfusion. This rise of glucose was used to quantify net glucose production. The specific activity of $\left[6-{ }^{3} \mathrm{H}\right]$ glucose declined throughout the perfusion. The change in $\left[6-{ }^{3} \mathrm{H}\right]$ glucose specific activity was used to quantify total glucose production. The incorporation of $\left[3-{ }^{3} \mathrm{H}\right] \mathrm{lac}-$ tate into glucose caused a continuous rise of both $\left[{ }^{14} \mathrm{C}\right]$ glucose and $\left[1-{ }^{14} \mathrm{C}\right]$ glucose and was used to quantify glucose production from lactate. Finally, liver glycogen content was determined in biopsies

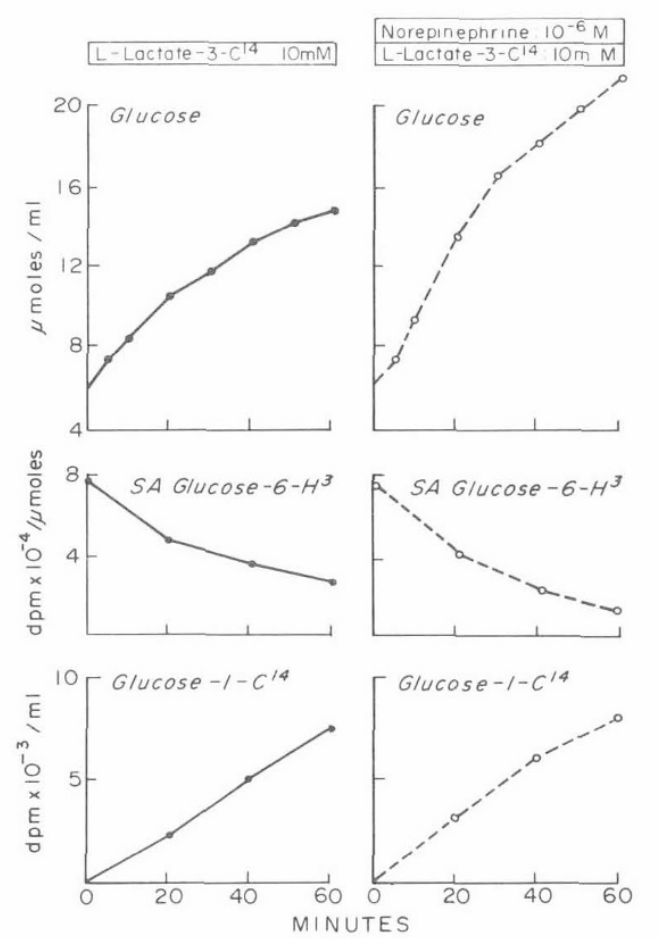

Fig. 1. Model for determining basal and norepinephrine-stimulated hepatic glucose production rates in perfused canine livers in the newborn period. Representative results from one pair of littermates 5 days old are illustrated. Glucose concentration in perfusate; $\left[6-{ }^{3} \mathrm{H}\right]$ glucose specific activity; and $\left[1-{ }^{14} \mathrm{C}\right]$ glucose formed from $\left[3-{ }^{14} \mathrm{C}\right]$ lactate are represented.

both before and following perfusion; the change of glycogen concentration was used to quantify glucose production from glycogen.

\section{ANALYSIS OF MEDIUM}

Samples $(0.5 \mathrm{ml})$ of the medium were withdrawn at 0 time and at $10-$ min intervals during perfusion and were placed in test tubes on ice. After centrifugation, the supernatants were stored at $-15^{\circ}$. All samples were precipitated with $10 \%$ perchloric acid and neutralized with $\mathrm{K}_{2} \mathrm{CO}_{3}$. Before column chromatography, supernatants were evaporated to dryness and reconstituted with fresh water to remove the $\mathrm{HO}^{3} \mathrm{H}$ which had been released from $\left[6-{ }^{3} \mathrm{H}\right]$ glucose during perfusion.

Glucose was determined spectrophotometrically by coupling the hexokinase and glucose-6-phosphate dehydrogenase reactions (27). The ${ }^{14} \mathrm{C}$ radioactivity on the $\mathrm{C}_{1}$ position of glucose was determined by oxidative decarboxylation of the 6-phosphogluconate generated in the glucose assay. The reaction mixture contained 6-phosphogluconic dehydrogenase, $0.5 \mathrm{U}$; glutamic acid dehydrogenase, $0.8 \mathrm{U} ; \alpha$-ketogłutarate, $1 \mu$ mol; and $\mathrm{NH}_{4} \mathrm{Cl}, 1$ $\mu \mathrm{mol}$; in a final volume of $1.2 \mathrm{ml}$ which included an aliquot from the assay of glucose. The labeled $\mathrm{CO}_{2}$ generated was collected in hydroxide of Hyamine (41) during a 1-hr period of incubation and for $30 \mathrm{~min}$ after addition of $1 \mathrm{M} \mathrm{NCl}$ and $0.5 \mathrm{M}$ sodium bicarbonate. The Hyamine was washed into vials containing toluene with $0.4 \%$, 2,5-diphenyloxazole scintillant for counting. External standards were used to correct for quenching. The recovery of $\left[1-{ }^{14} \mathrm{C}\right]$ glucose by this method was $88 \%$. Lactate was determined fluorometrically with lactate dehydrogenase (21).

Total radioactivity in glucose was separated from that in organic acids on microcolumns of the anion exchange resin AG-1X8 (42) as previously described (3). Glucose was eluted at $\mathrm{pH}$ 8; the organic acids were eluted with $0.02 \mathrm{~N} \mathrm{HCl}$. Radioactivity in glucose and lactate was determined by liquid scintillation counting with an external standard, using the commercial scintillation solution, Scintisol (43). The radioactive glucose included both 
$\left[{ }^{14} \mathrm{C}\right]$ glucose formed from $\left[{ }^{14} \mathrm{C}\right]$ lactate and $\left[6-{ }^{3} \mathrm{H}\right]$ glucose. The disintegration rates of the two isotopes were calculated after counting in two channels with an external standard to determine quenching. The recovery of labeled glucose or lactate from the column was $95 \%$. Specific activities of glucose and lactate are expressed disintegrations per $\mu \mathrm{mol}$. Cyclic AMP was determined in deproteinized perfusate by the method of Gilman $(15,18)$.

\section{ANALYSIS OF LIVER}

Liver glycogen content was measured in $100 \mathrm{mg}$ frozen liver tissue. The sample was homogenized in cold distilled water $(1: 25$ $\mathrm{w} / \mathrm{v}), 1.0 \mathrm{ml}$ hot $30 \% \mathrm{KOH}$ was added to $0.5 \mathrm{ml}$ homogenate, and the mixture was boiled for $30 \mathrm{~min}$. After the samples were cooled, 1 drop saturated $\mathrm{Na}_{2} \mathrm{SO}_{4}$ and $1.5 \mathrm{ml}$ cold $95 \%$ ethanol were added, and sample tubes were placed on ice for $1 \mathrm{hr}$. After centrifugation the precipitate was hydrolyzed by $0.5 \mathrm{ml} 1 \mathrm{~N} \mathrm{HCl}$ for $1 \mathrm{hr}$ at $100^{\circ}$. The hydrolyzed samples were then cooled and neutralized with $\mathrm{NaOH}$. Glucose was determined by the enzymatic method described above. Each value represents the mean of three separate 100-mg samples run in duplicate.

\section{ENZYMATIC ACTIVITIES}

With the exception of mitochondrial $\mathrm{CO}_{2}$ fixation, enzymatic activities were determined by assessing their maximal activity. There was no change in the maximal activities during $1 \mathrm{hr}$ of perfusion and all activities presented are mean values obtained by biopsy before perfusion of the liver. All activities are expressed as micromoles per min.g liver. Similar developmental patterns occurred when the data were expressed on the basis of protein content; statistical comparisons between results from control and hormonally treated livers were not altered by this method of expression. Mitochondrial $\mathrm{CO}_{2}$ fixation and pyruvate carboxylase activity were assayed in unfrozen liver specimens on the same day as the perfusion experiments. Fructose diphosphatase and phosphoenolpyruvate carboxykinase activities were assayed in frozen liver specimens stored at $-15^{\circ}$.

\section{FRUCTOSE-1,6-DIPHOSPHATASE (EC. 3.1.3.11)}

Frozen liver samples were homogenized 1:10 (w/v) in Tris- $\mathrm{HCl}$ buffer, $\mathrm{pH}$ 7.5. Homogenate enzymatic activity with those of glucose 7-phosphate dehydrogenase $(0.7 \mathrm{U} / \mathrm{ml})$ and phosphoglucose isomerase $(2.0 \mathrm{U} / \mathrm{ml})$ at $30^{\circ}(33)$. The incubation medium contained reagents and buffers at the following concentrations: Tris- $\mathrm{HCl}, 50 \mathrm{mM} ; \beta$-mercaptoethanol, $20 \mathrm{mM} ; \mathrm{MgSO}_{4}, 5 \mathrm{mM}$ fructose-1,6-diphosphate, $0.05 \mathrm{mM}$; NADP, $0.2 \mathrm{mM}$; and EDTA, $0.05 \mathrm{mM}$. Higher concentrations of fructose-1,6-diphosphate or $\mathrm{MgSO}_{4}$ inhibited the enzymatic activity

\section{MITOCHONDRIAL ISOLATION AND $\mathrm{CO}_{2}$ FIXATION}

Fresh liver samples were homogenized for $1 \mathrm{~min}$ in a solution of $0.3 \mathrm{M}$ sucrose- $N$ Tris(hydroxymethyl)-methyl-2-aminoethane sulfonic acid-EDTA buffer (sucrose TES-EDTA), pH 7.4 ( $5 \mathrm{ml}$ buffer solution/g liver). The homogenate was centrifuged at $650 \times g$ for 10 min to remove cellular debris; the supernatant was decanted and saved. Five milliliters of sucrose-TES-EDTA buffer were added to the sediment, which was rehomogenized and centrifuged as before. The second supernatant was decanted and added to the first supernatant and the combined supernatants were recentrifuged at $10,000 \times g$ for $20 \mathrm{~min}$. The sediment was resuspended in sucrose-TES-EDTA buffer to the original volume. This fraction contained "resuspended intact mitochondria."

The intact resuspended mitochondria were used to assay $\mathrm{CO}_{2}$ fixation at $37^{\circ}$ according to the method of Adam and Haynes (2). The final incubation solution contained reactants at the following concentrations: mitochondrial suspension (1:100); sodium pyruvate, $5 \mathrm{mM} ; \mathrm{MgCl}_{2}, 12.5 \mathrm{mM} ; \mathrm{K}_{2} \mathrm{SO}_{4}, 2.5 \mathrm{mM} ; \mathrm{KH}^{14} \mathrm{CO}_{3}, 12 \mathrm{mM}$ $(0.17 \mu \mathrm{Ci} / \mathrm{ml})$; and potassium phosphate, $8 \mathrm{mM}$. After precipita- tion with $5 \%$ tricholoroacetic acid (TCA), centrifugation, and removal of acid-labile ${ }^{14} \mathrm{CO}_{2}$ by bubbling $100 \% \mathrm{CO}_{2}$ through the sample, the acid-stable ${ }^{14} \mathrm{C}$ was determined by liquid scintillation.

\section{PYRUVATE CARBOXYLASE (EC. 6.4.1.1)}

An aliquot of intact resuspended mitochondria was sonically disrupted and used to assay pyruvate carboxylase activity according to the method of Adam and Haynes (2). Phosphotransacetylase and citrate synthetase were coupled with the pyruvate carboxylase reaction to trap labeled bicarbonate in citrate. The incubation solution for mitochondrial $\mathrm{CO}_{2}$ fixation was enriched with the following: adenosine triphosphate, $5 \mathrm{mM}$; lithium-CoA, $0.5 \mathrm{mM}$; and acetyl phosphate, $1.1 \mathrm{mM}$. The reaction was terminated and the sample counted as for mitochondrial $\mathrm{CO}_{2}$ fixation. Fixation of $\mathrm{CO}_{2}$ in the assay required acetyl-CoA generated from acetyl phosphate and lithium CoA. Appreciable enzymatic activity was present only in the mitochondrial fraction of the homogenate.

\section{PHOSPHOENOLPYRUVATE (PEP)-CARBOXYKINASE (EC. 4.1.1.32)}

Frozen liver samples were homogenized in 1:10 (w/v) Tris- $\mathrm{HCl}$ buffer, $\mathrm{pH}$ 7.5. PEP-carboxykinase was assayed at $30^{\circ}$ in $0.1-\mathrm{ml}$ homogenates by determining the incorporation of $\mathrm{H}^{14} \mathrm{CO}_{3}$ into acid-stable ${ }^{14} \mathrm{C}$ activity according to the method of Mersmann (22). The incubation medium contained Tris- $\mathrm{HCl}, 40 \mathrm{mM}, \mathrm{pH} 7.5$; inosine diphosphate $0.83 \mathrm{mM}: \mathrm{MnSO}_{4}, 2.5 \mathrm{mM}$; reduced glutathione, $1.67 \mathrm{mM} ; \mathrm{KH}^{14} \mathrm{CO}_{3}, 12 \mathrm{mM}(0.17 \mu \mathrm{Ci} / \mathrm{ml}) ; \mathrm{MgCl}_{2}, 6 \mathrm{mM}$; and PEP, $2.0 \mathrm{mM}$. The reaction was terminated with $5 \%$ TCA and subsequently handled in the same manner as mitochondrial $\mathrm{CO}_{2}$ fixation.

\section{CALCULATIONS}

Both the release of glucose and the incorporation of labeled lactate into glucose were linear; therefore, all calculations have been based on the assumption of zero order kinetics. All results were calculated on the basis of liver weight (micromoles per $\min \cdot g)$

$$
\begin{aligned}
& \text { TOTAL GLUCOSE PRODUCTION } \\
& \qquad \mathrm{P}_{\mathrm{t}}=\left(\frac{\mathrm{SA}_{0}}{\mathrm{SA}_{60}}-1\right) \frac{\mathrm{G} \cdot \mathrm{V}}{60 \cdot \mathrm{W}}
\end{aligned}
$$

where $\mathrm{P} v_{\mathrm{t}}=$ total glucose production, $\mathrm{SA}=$ specific activity of $\left[{ }^{3} \mathrm{H}\right]$ glucose in the medium (disintegrations per min per $\mathrm{ml}$ ) at zero time $\left(\mathrm{SA}_{0}\right)$, and $60 \mathrm{~min}\left(\mathrm{SA}_{60}\right), \mathrm{G}=$ the initial glucose concentration (micromoles per $\mathrm{ml}$ ), $\mathrm{V}=$ volume of perfusate (milliliters), and $\mathrm{W}=$ the weight of the liver in grams.

\section{NET GLUCOSE PRODUCTION}

$$
P_{n}=\frac{\left(G_{60}-G_{0}\right) V}{60 \cdot W}
$$

where $P_{n}=$ net glucose production, and $G=$ the concentration of glucose (micromoles per $\mathrm{ml}$ ) at zero time $\left(\mathrm{G}_{0}\right)$ and $60 \mathrm{~min}\left(\mathrm{G}_{60}\right)$.

\section{GLUCOSE PRODUCTION FROM GLYCOGEN}

$$
\mathrm{P}_{\mathrm{g}}=\frac{\mathrm{Gl}_{0}-\mathrm{Gl}_{60}}{60}
$$

where $\mathrm{Pg}=$ glucose production from glycogen, and $\mathrm{Gl}=$ the glycogen concentration expressed as equivalents of glucose (micromoles per $\mathrm{g}$ liver) at zero time $\left(\mathrm{Gl}_{0}\right)$ and at $60 \mathrm{~min}\left(\mathrm{Gl}_{60}\right)$.

\section{GLUCOSE PRODUCTION FROM LACTATE}

$$
P_{1}=\frac{\left(G_{60}^{*}-G_{0}^{*}\right) V}{2 \cdot S A_{1} \cdot 60 \cdot W}
$$

where $P_{1}=$ glucose production from lactate, $G^{*}=$ the concentra- 
tion of ${ }^{14} \mathrm{C}$ radioactivity in glucose (disintegrations per $\mathrm{ml}$ ) at zero time $\left(G_{0}^{*}\right)$ and $60 \mathrm{~min}\left(G_{60}^{*}\right), S_{1}=$ specific activity of lactate (disintegrations per $\mu$ mole), and 2 represents the molar quantity of lactate required to synthesize 1 mole glucose.
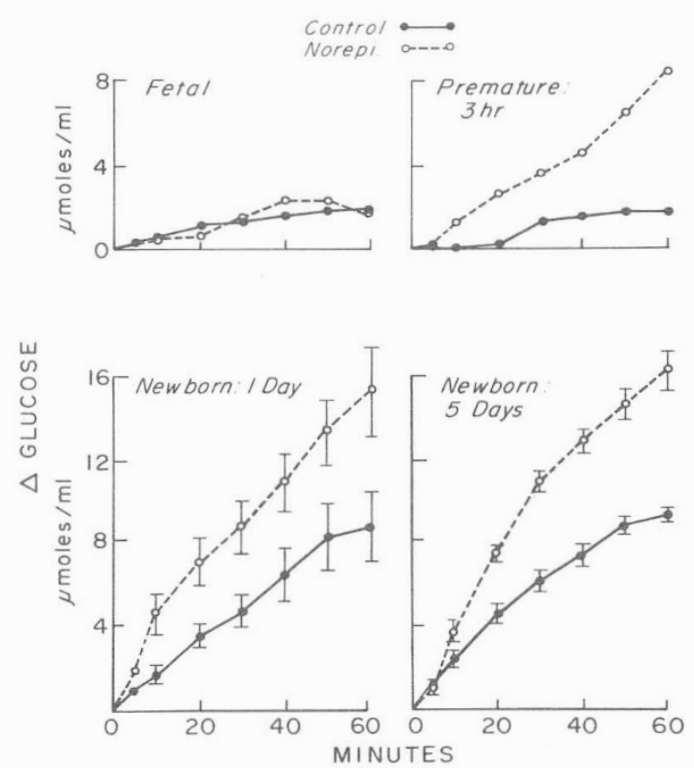

Fig. 2. Effects of gestational age and norepinephrine $\left(10^{-6} \mathrm{M}\right)$ on the increment of glucose above the initial medium concentration during perfusion of the 28 isolated canine livers. Fetal, $3 \mathrm{hr}, 1$ day, and 5 day refer to the age of animals (see Experimental Procedure). Control (- - ) and norepinephrine (Norepi.) (O_ - O) perfusions are represented. Vertical bars indicate SEM.

Table 1. Effects of gestational age and norepinephrine $(N E)\left(10^{-6} \mathrm{M}\right)$ on hepatic glucose metabolism (micromoles per min $\cdot g$ liver)
GLUCOSE UTILIZATION

$$
\mathrm{U}_{\mathrm{G}}=\frac{\left(\mathrm{G}_{0}^{\mathrm{t}}-\mathrm{G}_{60}^{\mathrm{t}}\right) \mathrm{V}}{\mathrm{SA}_{60} \cdot \mathrm{W}_{60}}
$$

where $\mathrm{U}_{\mathrm{i}}=$ glucose utilization, $\mathrm{SA}_{60}=$ specific activity of $\left[{ }^{3} \mathrm{H}\right]$ glucose in the medium (disintegrations per min per $\mu \mathrm{mol}$ ) at $60 \mathrm{~min}$, and $\mathrm{G}^{\mathrm{t}}=$, concentration of $\left[{ }^{3} \mathrm{H}\right]$ glucose (disintegrations per $\mathrm{ml})$ at zero time $\left(\mathrm{G}_{0}^{\mathrm{t}}\right)$ and $60 \mathrm{~min}\left(\mathrm{G}_{60}^{\mathrm{t}}\right)$.

\section{STATISTICS}

The difference between means was tested by the Student's $t$-test; linear regression lines and correlation coefficients were calculated using the programmable calculator 9810 STAT PAC 9810A (44).

\section{RESULTS}

\section{DEVELOPMENT OF HEPATIC GLUCOSE METABOLISM}

Hepatic Glucose Production. During perfusion of livers from all age groups, the glucose concentration in the medium rose continuously from the initial concentration of $6 \mathrm{mM}$ (Fig. 2). In livers from fetal and 3-hr premature dogs, medium glucose increased 2 $\mu \mathrm{mol} / \mathrm{ml}$ during control perfusion. By 1 day after spontaneous or vaginal delivery, medium glucose rose $8 \mu \mathrm{mol} / \mathrm{ml}$ during perfusion, reaching a final mean concentration of $14 \mu \mathrm{mol} / \mathrm{ml}$. Similar results were seen during perfusion of both 3 - and 5-day-old livers. Net glucose production rates were calculated from the changes in medium glucose concentration during perfusion (Table 1). The mean net fetal hepatic glucose production rate of $0.38 \mu \mathrm{mol} / \mathrm{min} \cdot \mathrm{g}$ is similar to that of the 3-hr premature livers; however, livers from l-day animals achieved mean production rates of $1.11 \mu \mathrm{mol} /$ $\min \cdot \mathrm{g}$.

\begin{tabular}{|c|c|c|c|c|c|c|c|}
\hline & \multirow{2}{*}{$n^{1}$} & \multicolumn{4}{|c|}{ Hepatic glucose production } & & \\
\hline & & \multicolumn{2}{|c|}{$\mathrm{Net}^{3}$} & \multicolumn{2}{|c|}{ Total $^{4}$} & \multicolumn{2}{|c|}{ Hepatic glucose utilization ${ }^{2}$} \\
\hline Fetal & 2 & 0.38 & 0.36 & 0.38 & 0.46 & 0.00 & 0.10 \\
\hline $3 \mathrm{hr}$ & 2 & 0.36 & 1.52 & 0.48 & 1.65 & 0.12 & 0.14 \\
\hline \multirow[t]{3}{*}{5 day } & 4 & $1.30 \pm 0.12$ & $2.04 \pm 0.11$ & $1.51 \pm 0.19$ & $2.71 \pm 0.36$ & $0.21 \pm 0.05$ & $0.66 \pm 0.13$ \\
\hline & & \multicolumn{6}{|c|}{ Hepatic glucose production } \\
\hline & & \multicolumn{2}{|c|}{ From glycogen ${ }^{6}$} & \multicolumn{2}{|c|}{ From lactate ${ }^{7}$} & \multicolumn{2}{|c|}{$\Sigma^{8}$} \\
\hline 3 day & 4 & $0.75 \pm 0.21$ & $0.94 \pm 0.17$ & $0.19 \pm 0.04$ & $0.24 \pm 0.07$ & $0.94 \pm 0.28$ & $1.18 \pm 0.07$ \\
\hline 5 day & 4 & $0.82 \pm 0.26$ & $1.44 \pm 0.28$ & $0.18 \pm 0.02$ & $0.24 \pm 0.05$ & $1.00 \pm 0.25$ & $1.68 \pm 0.24$ \\
\hline
\end{tabular}

${ }^{1}$ Results from littermate pairs perfused simultaneously. $n$ refers to number of pairs.

${ }^{2}$ Measured by disappearance of $\left[6-{ }^{3} \mathrm{H}\right]$ glucose.

${ }^{3}$ Measured by change in glucose concentration.

${ }^{4}$ Measured by change in $\left[6-{ }^{3} \mathrm{H}\right]$ glucose specific activity.

${ }^{5}$ Mean \pm SEM.

${ }^{6}$ Measured by change in glycogen concentration.

${ }^{7}$ Measured by incorporation of $\left[{ }^{14} \mathrm{C}\right]$ lactate into glucose.

${ }^{8}$ Calculated by addition of glucose production from lactate and glucose production from glycogen. 
Table 2. Hepatic glycogen concentration and enzymatic activities associated with gluconeogenesis during development

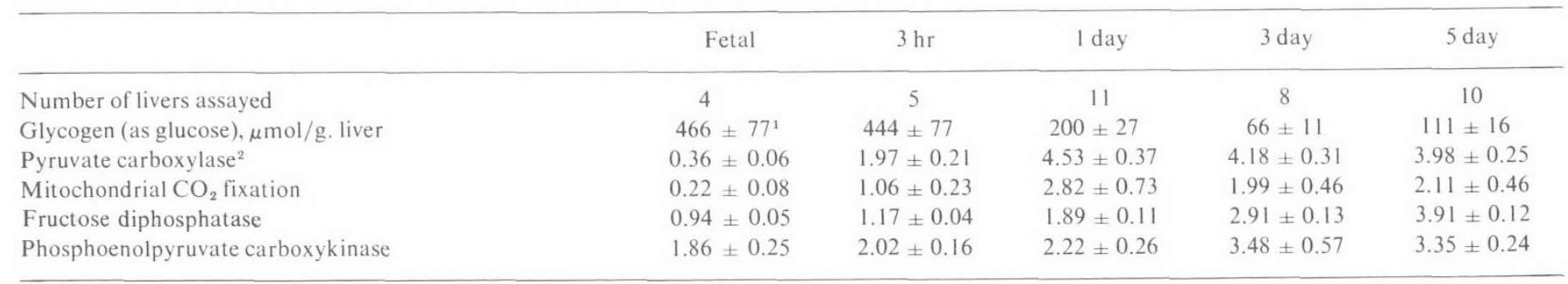

${ }^{1}$ Results are expressed as mean \pm SEM.

${ }^{2}$ All enzymatic activities expressed as micromoles per min.g liver.

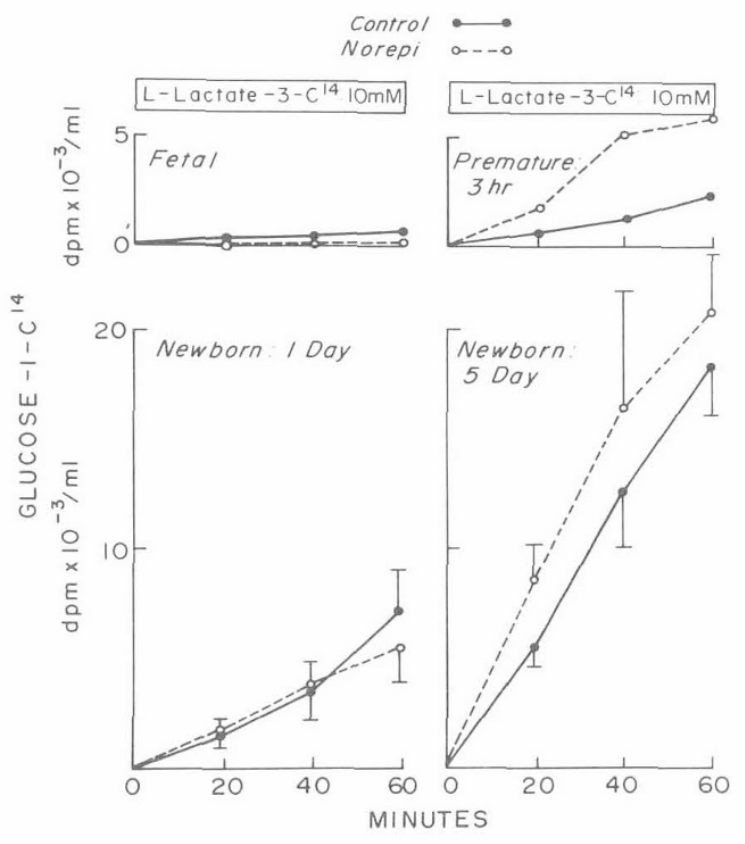

Fig. 3. Effects of gestational age and norepinephrine $\left(10^{-6} \mathrm{M}\right)$ on incorporation of $\left[3-{ }^{14} \mathrm{C}\right]$ lactate into $\left[1-{ }^{14} \mathrm{C}\right]$ glucose in isolated perfused

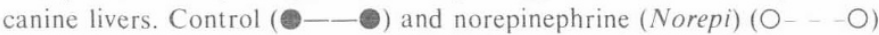
perfusions are represented. Vertical bars indicate SEM.

The specific activity of medium $\left[6-{ }^{3} \mathrm{H}\right]$ glucose (disintegrations per min per mol) declined during control perfusions (Fig. 1). Total glucose production, calculated from decline in $\left[6{ }^{3} \mathrm{H}\right]$ glucose specific activity, increased from rates below $0.48 \mu \mathrm{mol} / \mathrm{min}$ in fetal and $3-\mathrm{hr}$ premature livers to a mean level of $1.69 \mu \mathrm{mol} / \mathrm{min} \cdot \mathrm{g}$ in the day $I$ livers. Similar high total production rates during control perfusion were maintained during the subsequent 5 days.

Net glucose production and total glucose production follow a parallel developmental course, increasing from low levels during the first 3 postnatal hr to values 3-4 times higher later in the first day of life. Total glucose production rates exceeded net glucose production because glucose in the medium was utilized at measurable rates (Table 1).

Changes in Liver Glycogen. Liver glycogen concentration was relatively stable in the immediate postnatal period. In the $3 \mathrm{hr}$ after birth, hepatic glycogen decreased by only $22 \mu \mathrm{mol} / \mathrm{g}$ (Table 2 ). Subsequently, hepatic glycogen declined until it reached a mean level of $66 \mu \mathrm{mol} / \mathrm{g}$ on day 3. After that glycogen accumulated and its concentration in the liver increased twofold between the third and fifth day.

During control perfusion of both fetal and premature 3-hr liver, the glycogen concentration decreased by less than $30 \mu \mathrm{mol} / \mathrm{g} \mathrm{de}$ spite the large glycogen stores available. Beginning with day $l$ liver, the decrease in glycogen concentration during perfusion ranged
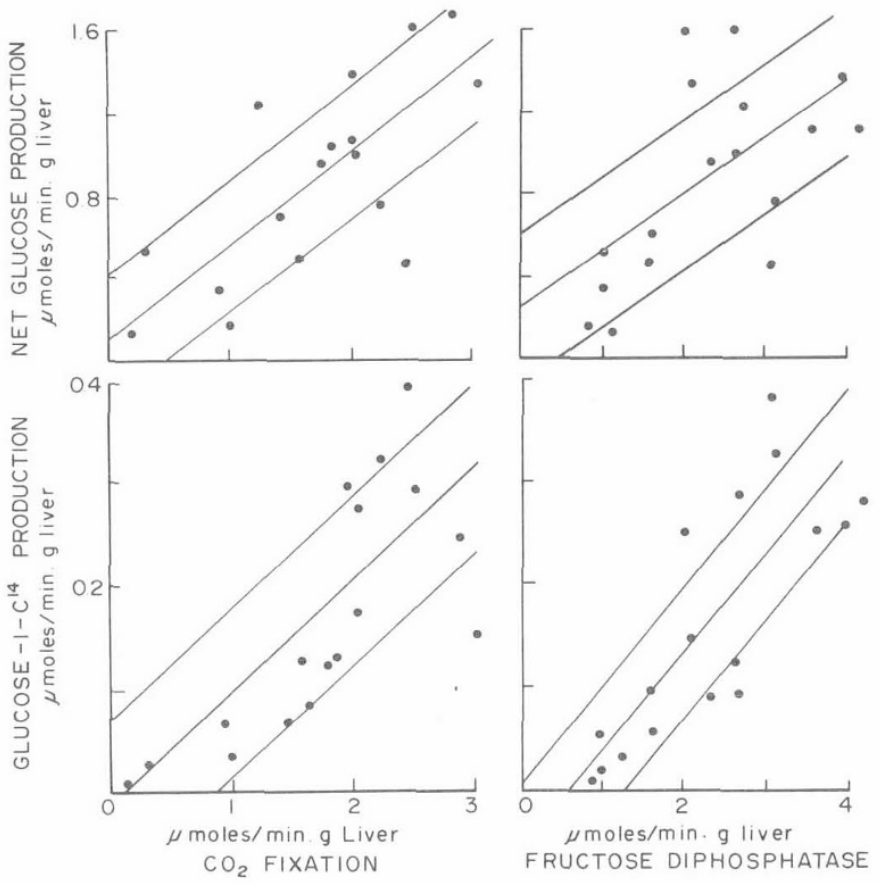

Fig. 4. Relationship of mitochondrial $\mathrm{CO}_{2}$ fixation and fructose-diphosphatase activity to net glucose production and glucose production from lactate. Values for mitochondrial $\mathrm{CO}_{2}$ fixation and fructose-diphosphatase activity were determined using liver biopsy specimens obtained before control perfusion. Mean \pm SD are represented by the continuous lines.

from $85 \mu \mathrm{mol} / \mathrm{g}$ on day $l$ to $30 \mu \mathrm{mol} / \mathrm{g}$ on day 3 . The glucose production rate from glycogen accounted for total and net production throughout the first day. At subsequent times, glycogenolysis alone did not account for glucose production (Table 1).

Glucose Production from Lactate. The incorporation of [3${ }^{14} \mathrm{C}$ llactate into glucose occurred at a relatively constant rate during perfusion as demonstrated by the linear rise of 11 $\left.{ }^{14} \mathrm{C}\right]$ glucose (Fig. 3) and of total $\left[{ }^{14} \mathrm{C}\right]$ glucose. The ratio of total $\left[{ }^{14} \mathrm{C}\right]$ glucose to $\left[1-{ }^{14} \mathrm{C}\right]$ glucose was $5.2 \pm 0.2($ mean $\pm \mathrm{SEM})$. Incorporation of lactate expressed in equivalents of glucose rose from the negligible rate in fetal liver to $0.19 \mu \mathrm{mol} / \mathrm{min} \cdot \mathrm{g}$ which accounted for $21 \%$ of net glucose production on day 3 .

Enzymatic activities associated with hepatic gluconeogenesis are presented in Table 2. Maximum pyruvate carboxylase activity rose rapidly from negligible fetal levels to approximately $4 \mu \mathrm{mol} / \mathrm{min} \cdot \mathrm{g}$ liver at 1 day of age and stabilized. Mitochondrial $\mathrm{CO}_{2}$ fixation, which provided a functional evaluation of mitochondrial pyruvate carboxylase activity, paralleled pyruvate carboxylase activity during development but was lower. Peak values for both were reached on the 1st day of life.

Phosphoenolpyruvate carboxykinase activity was substantial in fetal livers $(1.86 \mu \mathrm{mol} / \mathrm{min} \cdot \mathrm{g})$ and did not change during the first 
day of life. The activity rose on day 3 and 5 to levels of approximately $3.5 \mu \mathrm{mol} / \mathrm{min} \cdot \mathrm{g}$. In contrast, maximal fructosediphosphatase activity was $0.94 \mu \mathrm{mol} / \mathrm{min} \cdot \mathrm{g}$ in fetal livers and rose steadily between $3 \mathrm{hr}$ and 5 days of age to reach values of 3.91 $\mu \mathrm{mol} / \mathrm{min} \cdot \mathrm{g}$ liver.

Sources of Glucose and Correlations. The values for glycogen breakdown and lactate incorporation were added $(\Sigma$ glucose production rate) and compared with the glucose production rates in Table 1. For all developmental ages studied, the summed glucose production rate accounted for net glucose production during control perfusion.

In order to evaluate the role of enzymatic activities in the initiation of hepatic glucose production, the relationship of each enzymatic activity to net glucose production, production from glycogen, and production from lactate was examined (Table 2). Mitochondrial $\mathrm{CO}_{2}$ fixation correlated directly with net glucose production $(P<0.001)$, glucose production from glycogen $(P<$ $0.01)$, and glucose production from lactate $(P<0.01)$ as indicated in Fig. 4. In addition, net glucose production correlated with pyruvate carboxylase $(P<0.001)$ and fructose diphosphatase activities $(P<0.005)$ (Fig. 4). Even though gluconeogenesis accounted for a small proportion of net glucose production, glucose production from lactate correlated directly with net glucose production $(P<0.05)$.

\section{RESPONSES OF HEPATIC GLUCOSE PRODUCTION TO NOREPINEPHRINE}

The effect of norepinephrine (NE) on medium glucose concentration is illustrated in Fig. 2. When fetal livers were perfused the rise in glucose concentration was unaffected by NE. However, when the livers of littermates were perfused $3 \mathrm{hr}$ after surgical delivery the glucose concentration rose an additional $8 \mu \mathrm{mol} / \mathrm{ml}$ in response to NE. On days 1,3 , and 5, NE doubled the increment of glucose concentration which occurred during perfusion. Both net glucose production and total glucose production were accelerated by NE during the first 5 days of life (Table 1).

Norepinephrine did not stimulate glycogen breakdown in fetal livers perfused immediately after surgical delivery; however, at 3 $\mathrm{hr}$ of age, NE tripled the decline in glycogen concentration observed during control perfusion (Table 1). Subsequently, perfusion with NE increased glycogen breakdown at all times studied and the hormone-induced increase of net glucose production was accounted for by the increased rate of glycogen breakdown.

Norepinephrine had little effect on the incorporation of $\left[{ }^{14} \mathrm{C}\right] \mathrm{lac}-$ tate into glucose (Fig. 3). Although the incorporation in 3-hr liver apparently was increased somewhat by NE (0.05 vs. $0.09 \mu \mathrm{mol} /$ $\mathrm{min} \cdot \mathrm{g})$, glucose production from lactate shows small increases at all other ages studied which were statistically insignificant (Table 1). The relationship between net and $\Sigma$ glucose production rates was the same for norepinephrine perfusion as for control perfusions and is presented in Table 1. As indicated, the summed

Table 3. Effects of gestational age and norepinephrine $(N E)\left(10^{-6}\right.$ $M)$ on cyclic AMP production

Cyclic AMP production, $(\mathrm{pmol} / \mathrm{g} \text { liver })^{1}$

\begin{tabular}{lccc} 
& $n^{2}$ & Control & NE \\
\hline Fetal & 2 & 380 & 478 \\
3 hr & 2 & 312 & 564 \\
1 day & 3 & $351 \pm 50^{3}$ & $484 \pm 119$ \\
3 day & 4 & $303 \pm 40$ & $376 \pm 59$ \\
5 day & 3 & $419 \pm 109$ & $726 \pm 178$ \\
\hline
\end{tabular}

${ }^{1}$ Total cyclic AMP released during 60 min of perfusion.

${ }^{2}$ Results from littermate pairs perfused simultaneously. $n$ refers to number of pairs.

${ }^{3}$ Mean \pm SEM.
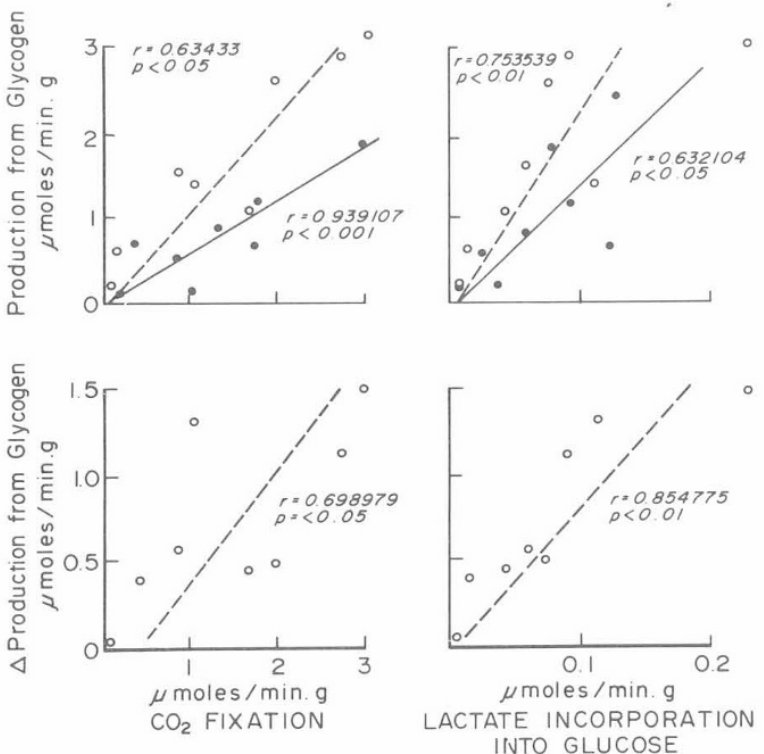

Fig. 5. Top panels correlate mitochondrial $\mathrm{CO}_{2}$ fixation or lactate incorporation into glucose with the rates of glucose production from glycogen on day 1 . Control $(-)$ and norepinephrine $(O)$ perfusions are represented. Regression lines are indicated for control (- - ) and norepinephrine (- - ) perfusions. Lower panels correlate $\mathrm{CO}_{2}$ fixation or lactate incorporation with the increment in the rate of glucose production from glycogen caused by norepinephrine on day 1 . The increment was determined by subtracting the decline of glycogen in the control liver from the decline in the paired norepinephrine-treated liver.

glucose production rate was not significantly different from net glucose production at any time.

Perfusion with norepinephrine increased hepatic cyclic AMP secretion modestly, but this rise was statistically significant only on the fifth day (Table 3). In contrast, norepinephrine perfusion did not result in a significant rise of gluconeogenesis at any developmental stage. Furthermore glycogen degradation did not correlate with cyclic AMP release, even when both were increased by norepinephrine.

During the 1st day of life, when glucose production was established, glycogen degradation correlated with $\mathrm{CO}_{2}$ fixation in livers perfused with norepinephrine as well as in controls (Fig. 5). Moreover, on day 1 , the incremental glycogen degradation resulting fron norepinephrine stimulation correlated with $\mathrm{CO}_{2}$ fixation $(P<0.05)$ and lactate incorporation into glucose $(P<0.01)$ as indicated in Figure 5.

Two livers were perfused with glucagon $\left(10^{-6} \mathrm{M}\right)$ on day 1 . The glucose production rate (mean net $=2.03 \mu \mathrm{mol} / \mathrm{min} \cdot \mathrm{g}$ ) was twice that of controls and was indistinguishable from that of livers perfused with norepinephrine. Lactate incorporation was similar to that in control and NE-treated livers $(0.13 \mu \mathrm{mol} / \mathrm{min} \cdot \mathrm{g})$.

\section{MAGNITUDE OF GLUCOSE PRODUCTION (TABLE 4)}

In Table 4, mean net hepatic glucose production by the isolated perfused canine liver on days 1,3 and 5 is compared with systemic glucose production rates measured by radioisotope dilution in newborn dogs of the same ages. As indicated, glucose production rates in newborn dogs resemble those of the isolated liver in the "unstimulated" state and during periods of pharmacologic stimulation.

\section{DISCUSSION}

\section{EFFECT OF DEVELOPMENT ON GLUCOSE PRODUCTION}

Throughout gestation, the mammalian fetus derives glucose transplacentally from maternal supplies. In the present study, 
Table 4. Compariso" of glucose production by newborn dog and isolated perfused canine liver (micromoles per min. $\mathrm{kg}$ body weight, mean $\pm S E M$ )

\begin{tabular}{|c|c|c|c|c|}
\hline Group & Method & $n$ & Control & Experimental \\
\hline A. Newborn dogs ${ }^{1}$ & In vivo & & & \\
\hline 1. Control:control & {$\left[2-{ }^{3} \mathrm{H}\right]$ Glucose $^{2}$} & 7 & $54.7 \pm 3.4$ & $48.7 \pm 2.3$ \\
\hline 2. Control:glucagon ${ }^{3}$ & {$\left[2-{ }^{3} \mathrm{H}\right]$ Glucose } & 7 & $52.7 \pm 2.7$ & $80.8 \pm 4.2$ \\
\hline B. Perfused liver & In vitro & & & \\
\hline 1. Control & Glucose release & 12 & $55.3 \pm 7.6$ & \\
\hline 2. Norepinephrine ${ }^{4}$ & Glucose release & 12 & & $99.4 \pm 13.3$ \\
\hline 3. Glucagon ${ }^{5}$ & Glucose release & 2 & & 106.0 \\
\hline
\end{tabular}

\footnotetext{
${ }^{1}$ Newborn dogs at 1,3 , and 5 days of age. All dogs were fed ad libitum from birth until 4 hr before study.

${ }^{2}$ Systemic glucose production measured by radioisotope dilution of tracer in a steady state during constant rate infusion.

${ }^{3}$ Glucagon infused continuously from $90-180 \mathrm{~min}$ of experiment at a rate of $3.3 \mu \mathrm{g} / \mathrm{min}$ to pups varying in weight from 190 to $457 \mathrm{~g}$.

${ }^{4}$ Norepinephrine $10^{-6} \mathrm{M}$.

${ }^{5}$ Glucagon $10^{-6} \mathrm{M}$.
}

spontaneous glucose production rates of isolated livers from the canine fetus or 3-hr-old newborn would have been insufficient for the maintenance of blood glucose in intact puppies after birth. Even though the hepatic glycogen reserves at birth exceeded those in fed adult dogs (4), postnatal acceleration of hepatic glucose production apparently required prior neural or hormonal stimulation of the liver.

Although the newborn dogs were fed ad libitum during the period of study, the capacity for hepatic glucose production was established during the first day, and the isolated liver released glucose spontaneously at rates above $1 \mu \mathrm{mol} / \mathrm{min} \cdot \mathrm{g}$ liver. Initially glucose production resulted from glycogen mobilization alone. Between the first and third day, hepatic glycogen declined and hepatic gluconeogenesis increased until it made a contribution to the glucose production rate. This postnatal increase of lactate incorporation into glucose correlated directly with the development of enzymatic activities associated with gluconeogenesis. In contrast to the rat where hepatic PEP-carboxykinase activity is rate-limiting for gluconeogenesis during development $(5,35)$, substantial PEP-carboxykinase activity was present in canine fetal liver at term. Fructose-diphosphatase activity also was relatively high in canine fetal liver; however, hepatic mitochondrial pyruvate carboxylase may have been the rate-limiting activity. Both pyruvate carboxylase activity and mitochondrial $\mathrm{CO}_{2}$ fixation were negligible in fetal liver, increased rapidly during the first day of life, and correlated with the rate of gluconeogenesis during perfusion. These results suggest that postnatal increase in the activity of pyruvate carboxylase is required for gluconeogenesis from lactate in canine liver.

Even though incorporation of lactate into glucose represented a relatively small proportion of total glucose production, both net glucose production and production rates from glycogen correlated directly with incorporation of lactate into glucose, mitochondrial $\mathrm{CO}_{2}$ fixation, pyruvate carboxylase activity, and fructose-diphosphatase activity. Furthermore, postnatal increases in both net glucose production and production from glycogen occurred only after the postnatal increases in mitochondrial $\mathrm{CO}_{2}$ fixation and pyruvate carboxylase activity. These interrelationships between glycogenolysis and gluconeogenesis may suggest that glycogenolysis and gluconeogenesis are initiated by a single event. Alternatively, the postnatwl acceleration of glycogenolysis and gluconeogenesis may be interdependent.

\section{EFFECT OF NOREPINEPHRINE ON HEPATIC GLUCOSE PRODUCTION}

The minimum concentration of epinephrine which is glycogenolytic in the adult dogs (14) exceeds physiologic plasma catecholamine levels in the dog (16). In addition, studies with the isolated perfused rat liver have demonstrated that pharmacological doses of the catecholamines are required to elicit modest hepatic glycogenolysis $(20,29)$. Thus, circulatory concentrations of cate- cholamines within the biologic range are not sufficient to affect hepatic glucose production directly.

Direct sympathetic innervation is involved, however, in the regulation of hepatic glycogen metabolism. Electrical stimulation of the splanchnic nerve in adrenalectomized dogs produces a hyperglycemic, glycogenolytic response (9). In addition, this glycogenolytic response has been duplicated by intramesenteric infusions of norepinephrine which result in portal venous levels of $10^{-6} \mathrm{M}(12)$. Since norepinephrine levels between $10^{-5}$ and $10^{-6} \mathrm{M}$ elevate glucose production to rates approaching maximum for the isolated perfused adult rat liver (13), a similar medium concentration was selected for use in the present study. These pharmacologic levels of norepinephrine stimulated glucose production by increasing glycogenolysis in livers isolated 3 or more hours after birth. In addition, there was a modest increase of cyclic AMP release into the medium, associated with this glycogenolytic response to norepinephrine. Such responses might be expected if glycogenolysis were mediated by $\beta$-adrenergic receptors. There was, however, no direct relationship between the cyclic AMP response and glycogenolysis, suggesting that $\alpha$-adrenergic receptors may have predominated $(25,31)$.

Although norepinephrine increased neonatal hepatic glycogenolysis within $3 \mathrm{hr}$ after birth, it did not accelerate fetal hepatic glycogenolysis. Similarly, splanchnic nerve stimulation of newborn calves before $12 \mathrm{hr}$ of age is less effective in initiating hepatic glycogenolysis than at an older age (11); hepatic glycogenolysis of newborn rats is unresponsive to stimulation by glucagon or cyclic AMP for $2 \mathrm{hr}$ after delivery (28). In the present study, the failure to respond immediately after birth to norepinephrine could result from a normal developmental event in which either the $\beta$-adrenergic, cyclic AMP-dependent or the $\alpha$-adrenergic, cyclic AMPindependent mechanisms are initiated postnatally. Such a lag. which occurs in the presence of adequate total phosphorylase activities (23), may represent an undeveloped step at any site between the adrenergic receptor and the activities of phosphorylase kinase activity.

Gluconeogenesis from lactate was not significantly accelerated by norepinephrine in fetal or newborn livers in the present study. In adult dogs, exogenous epinephrine seems to accelerate gluconeogenesis indirectly by increasing systemic lactate production (17); and splanchnic nerve stimulation has no hyperglycemic effect when hepatic glycogen is depleted (8). These results suggest that the direct effect of catecholamines upon canine hepatic gluconeogenesis is limited.

Even though incorporation of lactate into glucose was not accelerated significantly by norepinephrine in the isolated neonatal canine livers studied, a glycogenolytic response to norepinephrine may have depended on the establishment of hepatic gluconeogenesis. The glycogenolytic response to norepinephrine occurred only after pyruvate carboxylase activities rose from negligible levels to levels of approximately $2 \mu \mathrm{mol} / \mathrm{min} \cdot \mathrm{g}$. Furthermore, the glyco- 
genolytic response to norepinephrine during the first day of life correlated with $\mathrm{CO}_{2}$ fixation and lactate incorporation into glucose. Thus there appears to be an interaction between the glycogenolytic response to norepinephrine and the initiation of gluconeogenesis. Pharmacologic inhibition of gluconeogenesis would be necessary to define the nature of this relationship in the fetal and newborn period.

\section{SUMMARY}

The isolated perfused liver is a useful experimental model for examination of developing physiologic responses in the newborn dog. Even after isolation the liver produced glucose at physiologic rates approximating $50 \mu \mathrm{mol} / \mathrm{min} \cdot \mathrm{kg}$ body weight $(19,32)$ and the responses to pharmacologic hormonal stimulation resembled those in the intact puppy between 1 and 5 days of age (Table 4). Thus, the serial perfusion studies permitted quantification of the state which hepatic glucose production had attained based on prior conditions in the internal environment. Furthermore, the perfusion provided an abstracted model in which the response of the target organ to individual hormonal or pharmacologic agents could be examined. Based on these studies, hepatic glucose production is established in fed newborn dogs; the liver responds to catecholamine within $3 \mathrm{hr}$ of birth, and gluconeogenesis may be essential for the control of glucose production at physiologic rates.

\section{REFERENCES AND NOTES}

1. Adam, P. A. J.: Control of glucose metabolism in the human fetus and newborn infant. Advan. Metabol. Dis.. 5: 183 (1971).

2. Adam, P. A. J., and Haynes, R. C., Jr.: Control of hepatic mitochondrial $\mathrm{CO}_{2}$ fixation by glucagon, epinephrine and cortisol. J. Biol. Chem., 244: 6444 (1969).

3. Adam, P. A. J., Räihä, N., Rahiala, E.-L. and Kekomäki, M.: Oxidation of glucose and D-B-OH-butyrate by the early human fetal brain. Acta Paediat. Scand., 64: 17 (1975)

4. Allen, D. T., Kornhauser, D., and Schwartz, R.: Glucose homeostasis in the newborn puppy. Amer. J. Dis. Child., 1/2: 343 (1966).

5. Ballard, F. J., and Hanson, R. W.: Phosphoenolpyruvate carboxylase in developing rat liver. Biochem. J., 104: 866 (1967).

6. Ballard, F. J., and Oliver, I. T.: Glycogen metabolism in embryonic chick and neonatal rat liver. Biochim. Biophys. Acta, $71: 578$ (1963).

7. Dawkins, M. J. R.: Glycogen synthesis and breakdown in fetal and newborn rat liver. Ann. N. Y. Acad. Sci., 111: 203 (1963).

8. Edwards, A. V.: The glycogenolytic response to stimulation of the splanchnic nerves in adrenalectomized calves, sheep, dogs, cats, and pigs. J. Physiol., 213: 741 (1971)

9. Edwards, A. V.: The hyperglycemic response to stimulation of the hepatic sympathetic innervation in adrenalectomized cats and dogs. J. Physiol., 220. 697 (1972).

10. Edwards, A. V., and Silver, M.: The effect of asphyxia on the plasma glucose concentration in newborn calves. Biol. Neonat., 14: I (1969).

11. Edwards, A. V., and Silver, M.: The glycogenolytic response to stimulation of the splanchnic nerves in adrenalectomized calves. J. Physiol., 211: 109 (1970).

12. Edwards, A. V., and Silver, M.: Comparison of the hyperglycemic and glycogenolytic responses to catecholamines with those to stimulation of the hepatic sympathetic innervation in (he dog. J. Physiol., 223: 571 (1972).

13. Exton, J. H., Robison, G. A., Sutherland, E. W., and Park, C. R.: Studies on the role of adenosine $3^{\prime}, 5^{\prime}$-monophosphate in the hepatic actions of glucagon and catecholamines. J. Biol. Chem., 246: 6166 (1971).

14. Ezdinli, E. Z., and Sokol, J. E.: Comparison of glucagon and epinephrine effects in the dog. Endocrinology, 78: 47 (1966).

15. Gilman, A. G.: A protein binding assay for adenosine $3^{\prime}: 5^{\prime}$-cyclic monophosphate. Proc. Nat. Acad. Sci. U. S. A., 67: 305 (1970).

16. Goldfien, A., Zileli, M. S., Despoites, R. H., and Bethune, J. H.: The effect of hypoglycemia on the adrenal secretion of epinephrine and norepinephrine in the dog. Endocrinology, 62: 749 (1958).

17. Issekutz, B., Jr., and Allen, M.: Effect of catecholamines and methylprednisolone on the carbohydrate metabolism of dogs. Metabolism, 21: 48 (1972).
18. Kakiuchi, S., and Rall, T. W.: Studies on adenosine $3^{\prime}, 5^{\prime}$-phosphate in rabbit cerebral cortex. Molec. Pharmacol., 4: 379 (1968).

19. Kornhauser, D., Adam, P. A. J., and Schwartz, R.: Glucose production and utilization in the newborn puppy. Pediat. Res., 4: 120 (1970).

20. Lemberg, A. Wikinski, R. Izurieta, E. M: Halperin. H., Paglione, A. M. Neuman, M. P., and Jauregini, H.: Effects of prostaglandin E, and norepinephrine on glucose and lipid metabolism in isolated perfused rat liver. Biochim. Biophys. Acta, 248: 198 (1971).

21. Loomis, M. E.: An enzymatic fluorometric method for the determination of lactic acid in serum. J. Lab. Clin. Med., 67: 966 (1961).

22. Mersmann, H. J.: Glycolytic and gluconeogenic enzyme levels in pre- and postnatal pigs. Amer. J. Physiol., 220: 1297 (1971).

23. Schwartz, A. L., and Rall. T. W.: Hormonal regulation of glycogen metabolism in neonatal rat liver. Biochem. J., 134: 985 (1973).

24. Shelley, H. J.: Glycogen reserves and their changes at birth and in anoxia. Brit. Med. Bull., 17: 137 (1961)

25. Sherline, P.. Lynch. A., and Glinsmann, W. H.: Cyclic AMP and adrenergic receptor control of rat liver glycogen metabolism. Endocrinology, 91: 680 (1972).

26. Shimazu, T. and Amakawa, A. Regulation of glycogen metabolism in liver by the autonomic nervous system. III. Differential effects of sympathetic-nerve stimulation and of catecholamines on liver phosphorylase. Biochim. Biophys. Acta, 165: 349 (1968).

27. Slein, M. W.: Determination of glucose with hexokinase and glucose-6-phosphate dehydrogenase. In: H. V. Bergmeyer: Methods of Enzymatic Analysis, p. 117 (Academic Press, Inc., New York, 1963).

28. Snell, K., and Walker, D. G.: Temporal aspects of glucose metabolism in the rat at birth. Biochem. J., 130:60 (1972)

29. Sokol, J. E., Sarcione, E. J., and Henderson, A. M.: The relative potency of glucagon and epinephrine as hepatic glycogenolytic agents: studies with the isolated perfused rat liver. Endocrinology, 74: 930 (1964).

30. Swiatek, K. R.: Development of gluconeogenesis in pig liver slices. Biochim. Biophys. Acta, 252: 274 (1971).

31. Tolbert, M. E. M., Butcher, F. R., and Fain, J. N.: Lack of correlation between catecholamine effects on cyclic adenosine $3^{\prime}: 5^{\prime}$-monophosphate and gluconeogenesis in isolated rat liver cells. J. Biol. Chem., 248: 5686 (1973).

32. Varma, S., Nickerson, H., Cowan, J. S., and Hetenyi, G., Jr.: Homeostatic responses to glucose loading in newborn and young dogs. Metabolism, 22: 1367 (1973).

33. Wimhurst, J. M., and Manchester, K. L.: A comparison of the effects of diabetes induced with either alloxan or streptozotocin and of starvation on the activities in rat liver of the key enzymes of gluconeogenesis. Biochem. J., 120: 95 (1970).

34. Yarnell, G. R. Nelson, P. A. and Wagle, S. R. Biochemical studies in the developing embryo. I. Metabolism of gluconeogenic precursors. Arch. Biochem., 114: 539 (1966).

35. Yeung, D., and Oliver, I. T.: Development of gluconeogenesis in neonatal rat liver. Efect of premature delivery. Biochem. J., 105: 1229 (1967).

36. Yeung, D., and Oliver, I. T.: Factors affecting the premature induction of phosphopyruvate carboxylase in neonatal rat liver. Biochem. J., 108: 325 (1968).

37. Boston, Mass.

38. St. Louis, Mo

39. Model 1000, Ambec, Boulder, Colo.

40. Levophed, Winthrop Laboratories, New York, N, Y

41. Richmond Haas, Philadelphia, Pa.

42. Biorad, Berkeley, Calif.

43. Isolab, Inc., Akron Ohio.

44. Hewlett Packard, Loveland, Colo.

45. The authors are grateful to Alan Schwartz who performed the cyclic AMP assays in conjunction with Theodore W. Rall, Ph.D., M.D., Department of Pharma cology, Case Western Reserve University School of Medicine.

46. This work was presented in part at the Annual Meeting of the Society for Pediatric Research, San Francisco, California, May 1973. Abstracted in Pediat. Res. 7: 381 (1973).

47. The project was supported by a grant from the United States Public Health Service, National Institutes of Child Health and Human Development (HD-05740). Dr. Adam was supported by the National Institute of Arthritis and Metabolic Diseases, Research Career Development Award K4AM-37,485; and R. Chlebowski was supported by training grants from the National Institute of Child Health and Human Development (HD-00024) and from the Ford Foundation $(67-135)$. The work was performed by Dr. R. T. Chlebowski in partial fulfillment of the requirements for a $\mathrm{Ph} . \mathrm{D}$. degree in the Department of Reproductive Biology at Case Western Reserve University School of Medicine.

48. Requests for reprints should be addressed: P. A. J. Adam, M.D., Department of Pediatrics, Cleveland Metropolitan General Hospital, 3395 Scranton Rd.. Cleveland, Ohio 44109 (USA)

49. Accepted for publication July 3, 1975. 